\title{
Green Synthesis of Zinc Oxide Nanoparticles Using Hyptis Leaf Extract and Activated Carbon-Based Zinc Oxide Composite of Supercapacitor Applications
}

\author{
V. Raja ${ }^{1, *}$, G. Selvan ${ }^{1}$, R. Anbarasu' ${ }^{1}$ and S. Baskar ${ }^{2}$ \\ ${ }^{1}$ PG and Research Department of Physics, Thanthai Hans Roever College (Autonomous), Perambalur, India; \\ pirithishraja@gmail.com, selvan96@rediffmail.com, anbarasu.try102@gmail.com \\ 2Department of Physics, Paavendhar College of Arts and Science, Manivilundan, \\ Attur, Salem, India; sivabaskar85@gmail.com
}

\begin{abstract}
Objective: To prepare the zinc oxide nanoparticles using the extract of Hyptis suaveolens leaf by adopting the green synthesis methods. The prepared $\mathrm{ZnO}$ nanoparticles along with the activated carbon nanocomposite electrode will be used to fabricate supercapacitor cell. Methods/statistical analysis: Nanoparticles of $\mathrm{ZnO}$ were prepared using the green synthesis method. The structural and molecular characterizations were carried out using conventional techniques. The particle size of nanoparticles along with its elemental composition was determined using TEM-SAED and its optical transparency was studied. Finally, the nanocomposite of $\mathrm{ZnO}$ and activated carbon is subjected to the electrochemical impedance spectroscopy for understanding its supercapacitor properties. Findings: Hyptis suaveolens leaf extract was used in the preparation of $\mathrm{ZnO}$ nanoparticles and TEM confirms that the particle size was in the range of 10 and $200 \mathrm{~nm}$. An absorption peak at $376 \mathrm{~nm}$ was observed from the UV spectroscopy, and the sample is transparent in the visible region. The capacitance value of the prepared sample is estimated to be $184.8 \mathrm{~F} / \mathrm{cm}^{2}$ at $5 \mathrm{mV} / \mathrm{sec}$. Applications/improvements: Nanocomposites of $\mathrm{ZnO}$ and activated carbon with different mass ratios (1:1 to 1:3) were subjected to electrochemical impedance measurement, and from the estimated capacitance value $\left(184.8 \mathrm{~F} / \mathrm{cm}^{2}\right)$ it was found to be a potential candidate for the supercapacitor application.
\end{abstract}

Keywords: Hyptis suaveolens, Nano-Zinc Oxide, Supercapacitor, TEM, XRD

\section{Introduction}

Metal oxides (MO) have strong photocatalytic and photo oxidizing properties due to the presence of many active sites and fabrication of hydroxial radicals on their surface. $-\underline{-3}$ During the past decade, various physical and chemical techniques used in the synthesis of metal oxide nanostructures have been developed, including for the purpose of assessing thermal decomposition, chemical vapour deposition, electrochemical deposition, electrophortic deposition, co-precipitation, ultra sound, pulsed laser deposition, and anodization..$^{4-11}$ The conventional physical and chemical methods are costly, toxic, and their disposal pollutes the environment and creates several disadvantages for the application of nanoparticles in biomedical fields. To overcome the above defects, it is necessary to search for a nature-friendly approach for the synthesis of metal and metal oxide

${ }^{*}$ Author for correspondence 
nanoparticles. This green approach has emerged to be a cost-effective alternative to the conventional synthesis methods. Currently, the use of green organic compounds extracted from leaves, stem, flowers, fruits, or seeds as reductants have been reported by several researchers. $\underline{\underline{12}-\underline{20}}$ Apart from the plant extracts, pure organic compounds obtained from green products such as andrographolide, 21 Carboxylic curdlan, $\underline{22}$ Ellagic acid, and geraniin $\underline{23}$ have also been used for producing reducing agents that help in the immediate reduction of metal ions in nanostructured metal oxides. Among different nanostructured metal oxides, $\mathrm{ZnO}-\mathrm{NPs}$ attracts tremendous attention because of its excellent properties like wide direct band gap of $3.37 \mathrm{eV}$ at room temperature and high excitation binding energy of $60 \mathrm{meV} \cdot \underline{24}-\underline{26}$ It has a wide range of applications, including in plastics, $\underline{27}$ sensors,,$\underline{28}$ solar cells, $\underline{29}$ cosmetics, $\underline{\underline{30}}$ sunscreens, $\underline{31}$ and diagnostics. $\frac{32}{}$ Also, due to its low toxicity, $\mathrm{ZnO}$ has been listed $\underline{33}$ as "'Generally Recognized as Safe" (GRAS) by the U.S. Food and Drug Administration (21, CFR 182, 8991). Zinc oxide is a familiar energy storage device having high energy density of $650 \mathrm{~A} / \mathrm{g}$. Even though it has disadvantages such as formation of dendrite growth during consecutive cycling, which leads to decrease in life cycle, it is a promising electrode material for supercapacitor. The plant Hyptis suaveolens (L.) Poit belongs to the family Lamiaceae is native of Tropical America. The different parts of $H$. suaveolens plant, like the bark, seed, and leaves, are used to cure swellings, abscesses, haemorrhoids, and improve memory.

Sharma Prince $\underline{34}^{34}$ reported that the $H$. suaveolens contains many diverse phytochemicals like sterols, phenols, saponins, terpenes, alkaloids, and flavonoids and secondary metabolites like suaveolic acid, suaveolol, methyl suaveolate, $\beta$-sitosterol, ursolic acid, rosamarinic acid, methyl rosmarinate, oleanoic acid, 1,19 a-dihydroxyurs-2(3),12-dien-28-oic acid, 3 $\beta$-hydroxy lup-12-en-28oic acid, urs-12-en-3 $\beta$-ol-27-oic acid, and $3 \beta$-hydroxyl lup-20(29)-en-27-oic acid. Therefore, H. suaveolens leaf extract was used as a reducing agent in the phytomediated synthesis of $\mathrm{ZnO}$ nanoparticles. Hence, the present work aims to develop the green synthesis of $\mathrm{ZnO}$ nanoparticle using $H$. suaveolens leaf extract based on the green chemistry approach. This approach has advantages such as low-cost precursor and a product that is high in purity and of more quantity. It does not require costly equipment and does not use any intermediate substance (any base groups); additional advantages include its rapidity and environment-friendly approach.

\section{Materials and Methods}

\subsection{Preparation of Hyptis suaveolens Leaf Extract}

Hyptis suaveolens were collected from Arumbavur, Perambalur District, India. They were cleaned with tripledeionized water and cut into small pieces. Five grams of the fresh leaf pieces were extracted with $100 \mathrm{ml}$ deionized water in a reflux condenser for $30 \mathrm{~min}$. After $30 \mathrm{~min}$, the extract was cooled to room temperature (approximately $30^{\circ} \mathrm{C}$ ). Then the solution was filtered through Whatman filter paper, and the resultant filtrate was refrigerated for further use.

\subsection{Eco-friendly Synthesis of Zinc Oxide Nanoparticles}

Zinc nitrate was acquired from Sigma-Aldrich. The freshly prepared mixture of leaf extract and $0.01 \mathrm{M}$ Zinc nitrate solution in the ratio of 1:4 was added in a conical flask and stirred at room temperature for $4 \mathrm{~h}$. The resultant mass was dried in hot air oven at $110^{\circ} \mathrm{C}$. The yellow-coloured paste thus obtained was finally calcined at $400^{\circ} \mathrm{C}$ to get fine crystals of $\mathrm{ZnO}-\mathrm{NPs}$ and stored in air-free containers for further characterization. Synthetic route of formation of Hyptis-mediated Zinc oxide nanoparticle is shown in Figure 1.

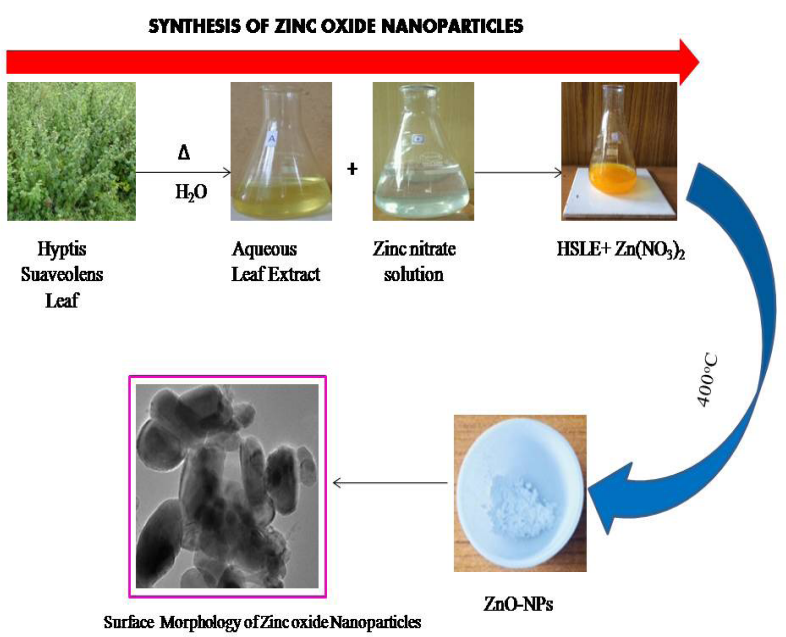

Figure 1. Schematic illustration of zinc oxide nanoparticles synthesis process. 


\subsection{Preparation of Hyptis suaveolens Activated Carbon}

$H$. suaveolens leaves were first washed several times with double-distilled water to remove dust, soil, and suspended impurities. The material was ground using pestle and mortar to turn it into fine particles. About $100 \mathrm{~g}$ of powdered fine materials was mixed with 50 $\mathrm{ml}$ of concentrated sulphuric acid and kept at room temperature for 1 day. The dried material was washed with double-distilled water for removing excess of acid. Finally, material was dried in $110^{\circ} \mathrm{C}$ for $14 \mathrm{~h}$ to remove moisture and kept in closed bottle.

\subsection{Preparation of AC- $\mathrm{ZnO}$ Electrode}

Activated carbon was mixed with $\mathrm{ZnO}$ in three different ratios $(1: 3,1: 2,1: 1)$ by using a paste made out of mixing n-methylpyrrolidone with polyvinylidiene fluoride. After that, AC-ZnO composite paste was applied with a brush to pre-weighted stainless steel current collector and dried at $25^{\circ} \mathrm{C}$.

\subsection{Characterization of Hyptis-mediated $\mathrm{ZnO}-\mathrm{NPs}$}

UV-1601 Shimadzu spectrophotometer was used to record $\mathrm{UV}-\mathrm{Vis}$ spectrum and confirm the formation of $\mathrm{ZnO}$ NPs. FT-IR spectra of HSLE and Hyptis-mediated ZnONPs were recorded using BRUKER-FTIR-TENSOR-27 spectrophotometer with frequency ranging from 400 to $4000 \mathrm{~cm}^{-1}$ in $\mathrm{KBr}$ matrix. The surface morphology of synthesized $\mathrm{ZnO}-\mathrm{NPs}$ was examined by JEOL JSM 6390. Scanning electron microscope (SEM) instrument operated at an accelerating voltage at $10 \mathrm{kV}$. The elemental composition of synthesized ZnO-NPs was done on SEM instrument equipped with thermo EDX attachment. The synthesized ZnO-NPs were characterized by HR-TEM techniques with the help of JEOL JEM 2100 instrument. The size of ZnO-NPs in HR-TEM image was measured by using the image J software. The biosynthesised $\mathrm{ZnO}$ NPs were analysed with XRD Gonimeter (SHIMADOModel XRD 6000). The scanning was done in the region of $2 \theta$ between $20^{\circ} \mathrm{C}$ and $90^{\circ} \mathrm{C}$ at $0.05^{\circ} \mathrm{C} / \mathrm{min}$, and the time constant was 2 s. $\mathrm{CH}$ electrochemical analyser Model $604 \mathrm{D}$ was used to record the Nyqyist curve. A threeelectrode cell assembly was used. Platinum and saturated calomel electrodes (SCE) were used as counter electrode and reference electrode, respectively. AC- $\mathrm{ZnO}$ composite electrode was used as the working electrode.

Electrochemical experiments were carried out by electrochemical impedance spectroscopic (EIS). AC impedance measurements were performed in the frequency range of $0.01 \mathrm{~Hz}$ to $100 \mathrm{KHz}$ with amplitude of $5 \mathrm{mV}$ peak-to-peak using AC signal.

\section{Results and Discussion}

\subsection{UV-Vis Spectral Analysis}

UV-Vis spectroscopy is an effective tool for analysing the formation of metal nanoparticles in aqueous solution. UVVis spectrum of the H. suaveolens leaf extract, H. suaveolens, Zinc Nitrate, and biosynthesized $\mathrm{ZnO}$ nanoparticles is shown in Figure 2. The SPR band of $\mathrm{ZnO}$-NPs at 376 $\mathrm{nm}$ confirms the formation. The SPR absorption is due to the oscillation of the free conduction band electrons excited by the incident electromagnetic radiation. This type of resonance is observed when the wavelength of the incident light far exceeds the diameter of particles. The sharp peak indicates the uniform size of the synthesized particles. This is in agreement with the reported studies on the biosynthesis of zinc oxide nanoparticles (absorption peak at $374 \mathrm{~nm}$ ) using various plant extracts,,$\underline{36}$ which confirmed the presence of $\mathrm{ZnO}$ nanoparticles.

\subsection{Role of Reductant Functional Groups in the Green Synthesis of $\mathrm{ZnO}$-NPs}

FT-IR spectra of the $H$. suaveolens leaf extract and biosynthesised $\mathrm{ZnO}-\mathrm{NPs}$ were shown in Figure 3a \&

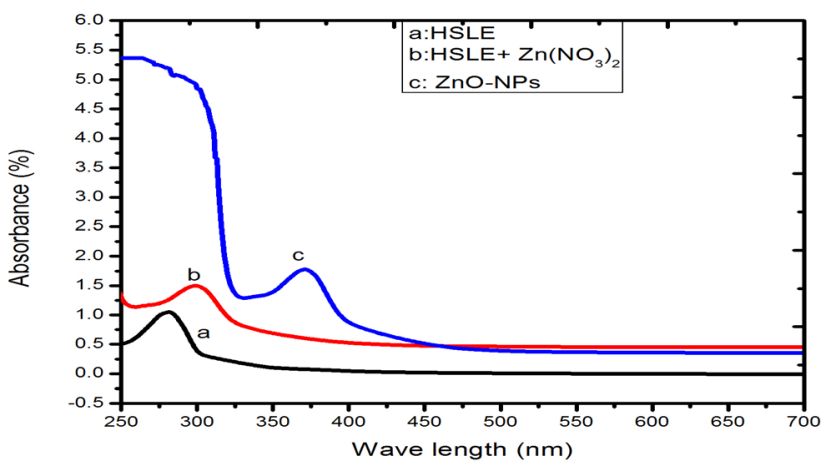

Figure 2. UV-Visible spectrum of Hyptis suaveolens leaf extract (a), $H$. suaveolens leaf extract with zinc nitrate (b), and $\mathrm{ZnO}-\mathrm{NPs}(\mathrm{c})$. 


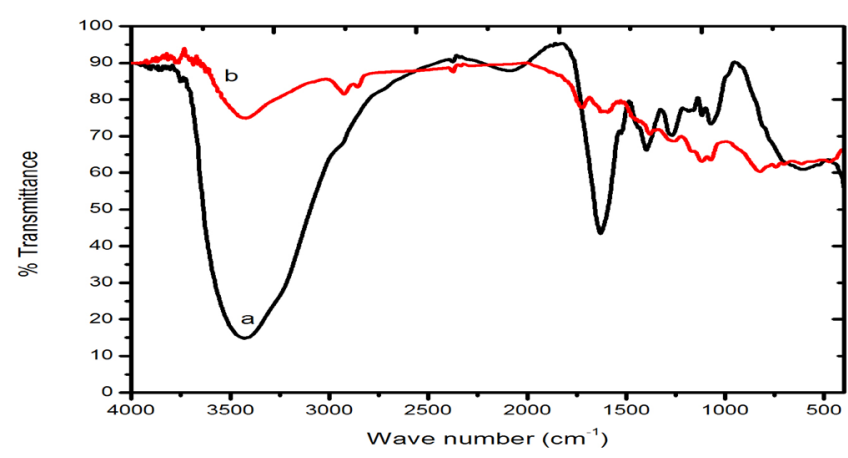

Figure 3. FT-IR spectrum of LLLE (a) and Hyptismediated $\mathrm{ZnO}-\mathrm{NPs}$ (b).

3b. FT-IR spectra of the $H$. suaveolens spectra reveal several absorption bands at $3425,1631,1395,1286,1116$, 1070 , and $607 \mathrm{~cm}^{-1}$ along with other small bands. These bands correspond to $-\mathrm{NH}, \mathrm{C}=\mathrm{O}$ group, $\mathrm{C}-\mathrm{H}$ scissoring and bending modes in the hydrocarbon chains, $\mathrm{C}=\mathrm{O}$ stretching in $\mathrm{C}-\mathrm{O}-\mathrm{C}, \mathrm{C}-\mathrm{N}$ stretching vibrations, and aromatic carbon-carbon triple bond. FT-IR spectra of Zinc oxide nanoparticles reveal a weak absorption at $3,434 \mathrm{~cm}^{-1}$ and $2,931 \mathrm{~cm}^{-1}$, which can be assigned to aliphatic asymmetric $\mathrm{C}-\mathrm{H}$ stretching vibrations and $-\mathrm{C}-\mathrm{H}$ stretching of carboxylic acids. The peak at $1745 \mathrm{~cm}^{-1}$ corresponds to $\mathrm{C}=\mathrm{O}$ stretching vibrations of carbonyl group. The peak at $610 \mathrm{~cm}^{-1}$ may be due to $\mathrm{C} \equiv \mathrm{C}$ stretching vibrations. The band at $471 \mathrm{~cm}^{-1}$ confirms stretching vibrations of metal oxygen [ $\mathrm{Zn}-\mathrm{O}]$ bond. $\underline{36}, \underline{37}$

\subsection{SEM and EDX Studies}

Scanning electron microscope (SEM) analysis of the Hyptis-mediated nanoparticles predicts the shape, size, and morphology of the biosynthesised nanoparticles. It is evident from Figure 4a that synthesised nanoparticles have Wurtzite hexagonal shape with particle size in the range of 10 to $70 \mathrm{~nm}$. The EDX spectrum of biosynthesised $\mathrm{ZnO}-\mathrm{NPs}$ as shown in Figure $4 \mathrm{~b}$ confirms the elemental composition of $\mathrm{ZnO}$ nanoparticles having $49 \% \mathrm{Zn}$ and $51 \% \mathrm{O}$ and no other signals present reveal the high purity of synthesised $\mathrm{ZnO}$-NPs without impurities.

\subsection{HR-TEM Analysis}

The HR-TEM analysis of biosynthesised ZnO-NPs explains the size and morphology of $\mathrm{ZnO}-\mathrm{NPs}$. Figure 5 shows the TEM image of biosynthesized $\mathrm{ZnO}$-NPs. The image reveals hexagonal (Wurtzite) shape of $\mathrm{ZnO}-\mathrm{NPs}$

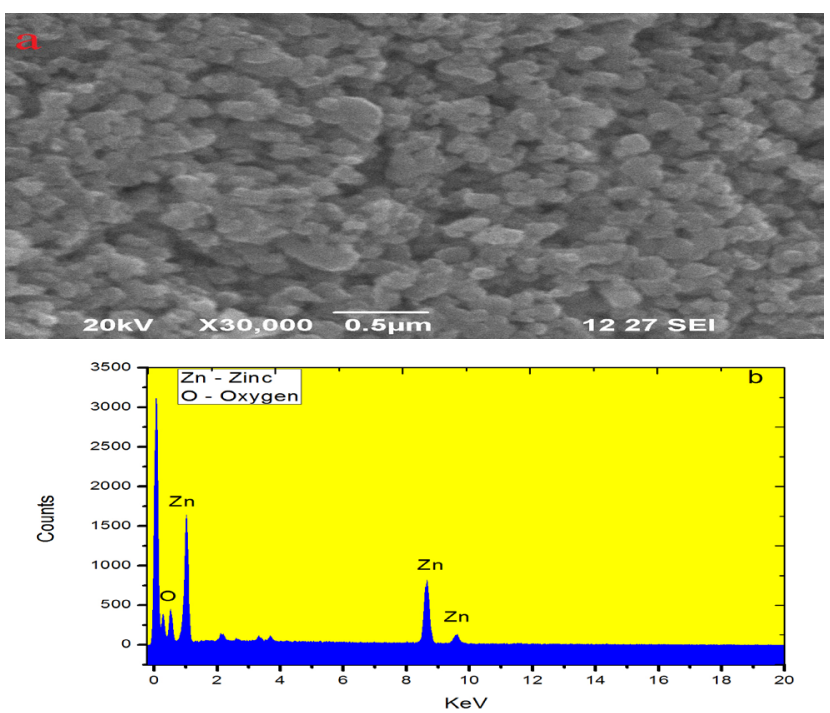

Figure 4. (a) SEM image of ZnO-NPs, (b) EDX spectra of pure $\mathrm{ZnO}-\mathrm{NPs}$.

with the particle size in the range of 10 to $200 \mathrm{~nm}$, which is in accordance with XRD data. The agglomeration of $\mathrm{ZnO}$-NPs is due to high surface energy because of its synthesis in aqueous medium and also possibly due to densification resulting in narrow space between particles. $\underline{36}-\underline{38}$ The selected area (electron) diffraction (SAED) pattern suggested that the particles are highly crystalline in nature and also display an arrangement of rings containing spots, indicating that nanoparticles have a bigger grain size, uniform shape, and are polycrystalline in nature.

\subsection{XRD Studies}

The XRD analysis of the Hyptis-mediated Zinc oxide nanoparticles reveals the crystallographic structure,

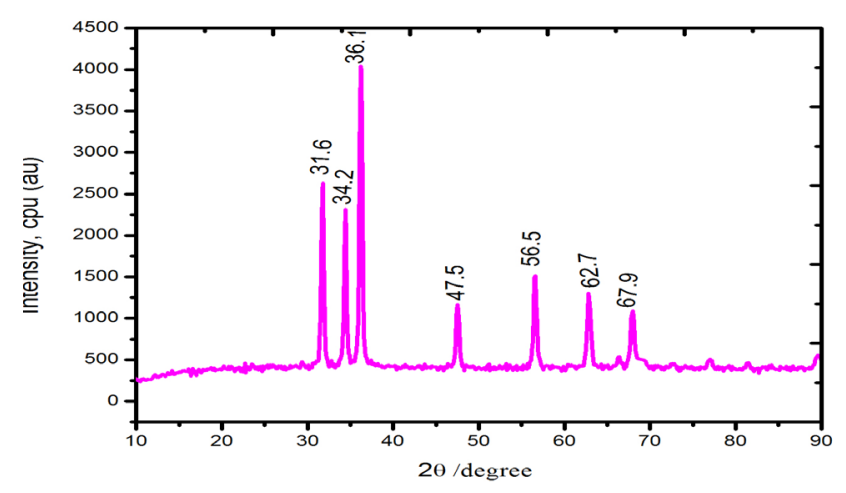

Figure 6. XRD patterns of Hyptis-mediated ZnO-NPs. 

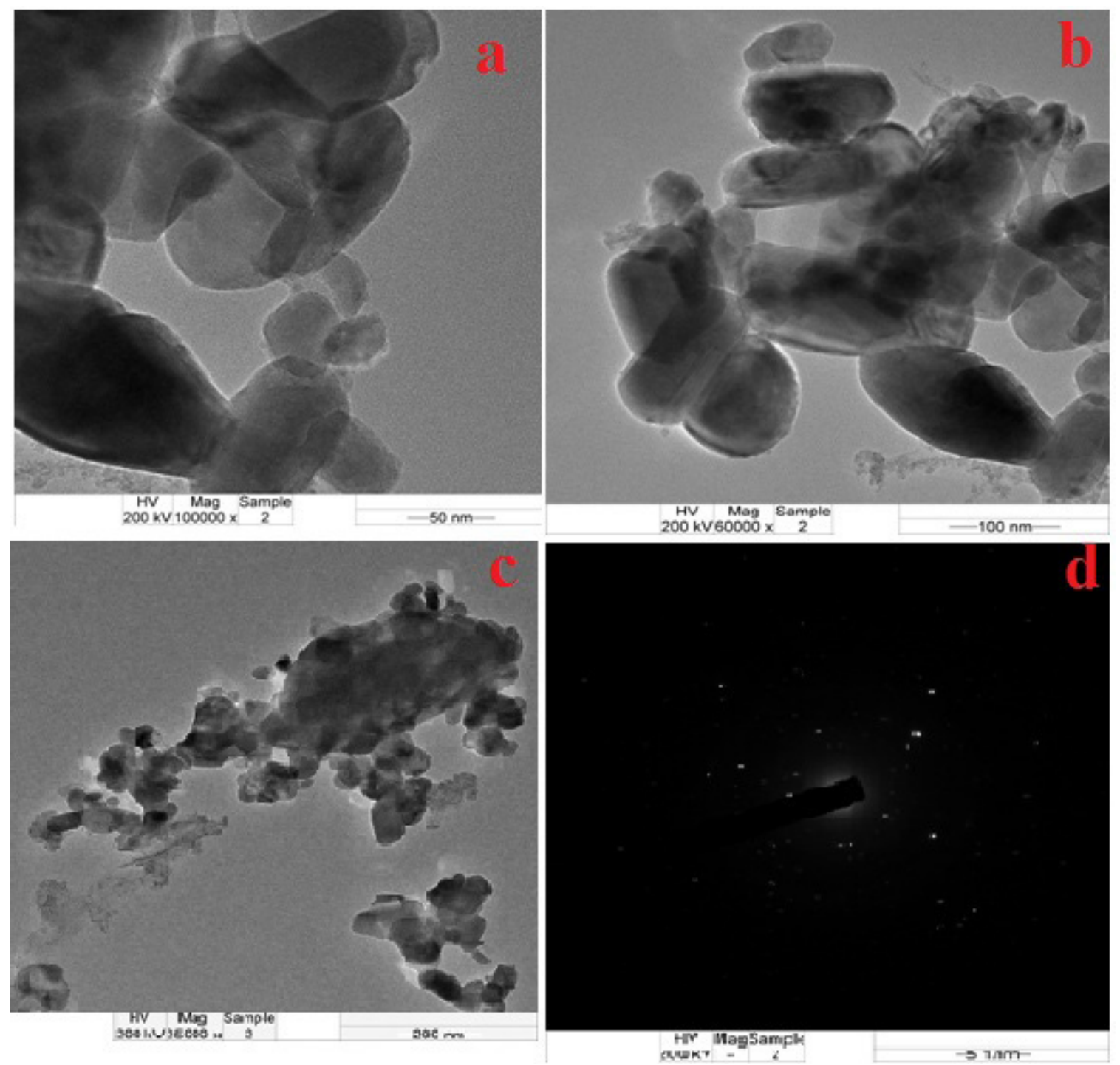

Figure 5. HR-TEM image of ZnO-NPs: (a) $50 \mathrm{~nm}$, (b) $100 \mathrm{~nm}$, (c) $200 \mathrm{~nm}$, and (d) SAED patterns of ZnO-NPs.

chemical composition, and physical properties of the ZnO-NPs. The obtained diffraction peaks at 32.01, 34.7, $37,47.48,56.9,63.1,66.2,69.4$, and 77.2 as shown in Figure 6 correspond to miller indices of 100, 002, 101, $102,110,103,112,201$, and 202 planes, respectively. The obtained results were in good agreement with JCPDS file No. 036-1451 confirming the hexagonal Wurtzite structure. .37 The clear intense peak obtained indicates the high purity and crystalline nature of the synthesized ZnO-NPs.

From the XRD pattern, high intensity peak at 101 plane is assigned to be the characteristic peak of $\mathrm{ZnO}$ NPs. No other diffraction peaks are identified, suggesting the purity of the synthesized $\mathrm{ZnO}-\mathrm{NPs}$.

\subsection{Electrochemical Impedance Spectroscopy (EIS)}

Electrochemical impedance spectroscopy (EIS) is an essential tool to investigate the impedance differences in various ratios of $\mathrm{AC}-\mathrm{ZnO}(1: 3,1: 2$, and 1:3) electrode. Figure 7 reveals the Nyquist plots of the $\mathrm{AC}-\mathrm{ZnO}$ with two different ratios [1:3, 1:2] in $0.1 \mathrm{M} \mathrm{Na}_{2} \mathrm{SO}_{4}$. A distinctive semicircle has been observed in $\mathrm{AC}-\mathrm{ZnO}$ (1:3 and 1:2), suggesting a single charge-transfer process taking place among the working material and electrolyte. The charge transfer resistance and specific capacitance values of $\mathrm{AC}-\mathrm{ZnO}$ electrodes are given in Table 1 . The charge transfer resistance increased with an increase 
AQ2

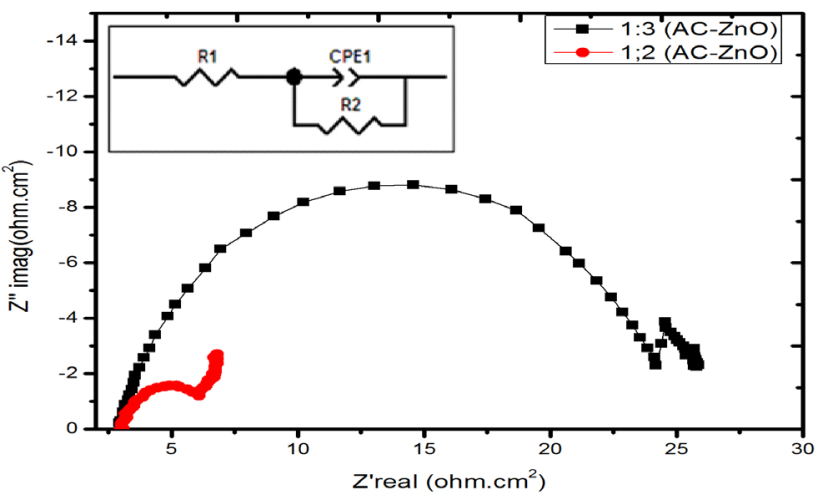

Figure 7. Impedance plots for $\mathrm{AC}-\mathrm{ZnO}$ composites at compositions of $1: 3$ and $1: 2$ and inset shows the equivalent circuit model.

Table 1. Electrochemical impedance parameters for AC-ZnO electrode in $0.1 \mathrm{M} \mathrm{Na}_{2} \mathrm{SO}_{4}$

\begin{tabular}{|l|l|l|l|}
\hline Materials & $\begin{array}{l}\text { Scan rate } \\
(\mathrm{mV} / \text { Sec. })\end{array}$ & $\begin{array}{l}\text { Charge transfer } \\
\text { resistance }\left(\mathrm{cm}^{2}\right)\end{array}$ & $\begin{array}{l}\text { Capacitance } \\
\left(\mathrm{F} / \mathrm{cm}^{2}\right)\end{array}$ \\
\hline AC-ZnO (1:3) & 5 & 24.1 & 7.8 \\
\hline AC-ZnO (1:2) & 5 & 4.0 & 2.5 \\
\hline AC-ZnO (1:1) & 5 & 2.0 & 184.8 \\
\hline
\end{tabular}

in the content of $\mathrm{ZnO}$ in $\mathrm{AC}-\mathrm{ZnO}$ composite mixture. Impedance diagrams were obtained for $\mathrm{AC}-\mathrm{ZnO}(1: 1)$ electrode as working electrode in $0.1 \mathrm{M} \mathrm{Na}_{2} \mathrm{SO}_{4}$ (Figure 8). A linear part is obtained at low frequency and a semicircle in the high-frequency region. The capacitance value increases at low frequencies due to a large number of ions

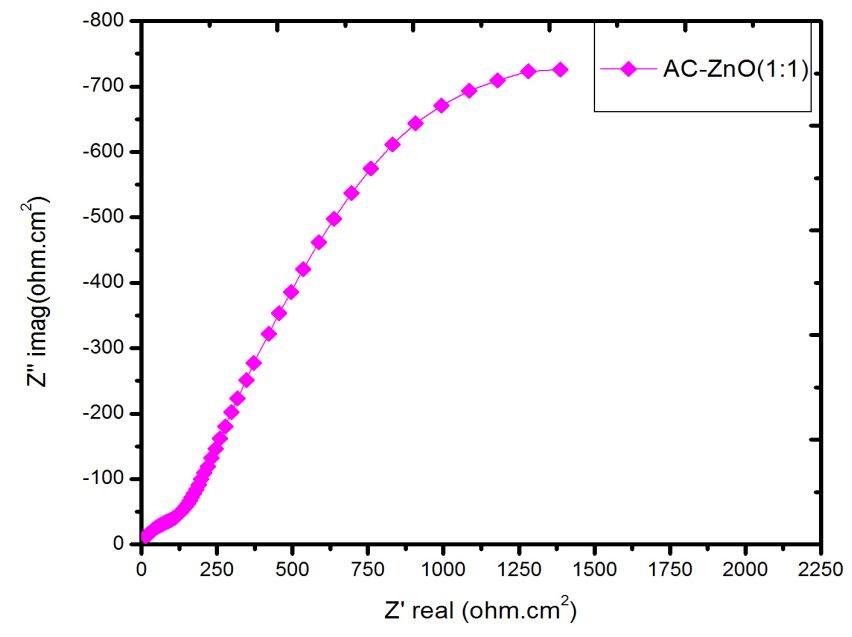

Figure 8. Impedance plots for AC- $\mathrm{ZnO}$ composites at 1:1 mass ratio. moving which cause a decrease in the bulk resistance of the capacitor. The semicircle results from the parallel combination of resistance and capacitance, and the linear region is due to Warburg impedance. In the low-frequency region, the linear region leans more towards imaginary axis, and this indicates good capacitive behaviour. From the figures it can be seen that the diameter of the semicircle (1:1 AC-ZnO) decreased compared to the other two compositions (2:1 and 3:1 AC-ZnO), which suggests an increase in the available large surface area on $\mathrm{AC}-\mathrm{ZnO}$ (1:1 ratio) and less restriction in the electron transfer process. Hence, AC- $\mathrm{ZnO}$ composite electrode is an excellent supercapacitor in energy storage devices.

\section{Conclusion}

In the present work, we report the green synthesis of ZnO-NPs from Zinc nitrate and H. suaveolens leaf extract. The biosynthesised ZnO-NPs was found to have Wurtzite hexagonal structure with particle size in the range of 20 to $200 \mathrm{~nm}$.

$\mathrm{X}$-ray diffraction analysis revealed the distinctive facets $(100,002,101,102,110,103,112,201$, and 202 planes) of $\mathrm{ZnO}-\mathrm{NPs}$. The prepared AC-ZnO composite was shown to be an excellent choice for material with good conductivity with $0.1 \mathrm{M} \mathrm{Na}_{2} \mathrm{SO}_{4}$ as the electrolytes for its application in an energy storage device such as a supercapacitor.

\section{References}

1. Vidya C, Chandra Prabha MN, Antony Raj MAL. Green mediated synthesis of zinc oxide nanoparticles for the photocatalytic degradation of Rose Bengal dye. Environ Nanotechnol Monit Manag. 2016;6:134-8.

2. Ishwarya R, Vaseeharan B, Kalyani S, Banumathi B, Govindarajan M, Alharbi NS, et al. Facile green synthesis of zinc oxide nanoparticles using Ulva lactuca seaweed extract and evaluation of their photocatalytic, antibiofilm and insecticidal activity. J Photochem Photobiol B. 2018;178:249-58.

3. Matinise N, Fuku XG, Kaviyarasu K, Mayedwa N, Maaza M. ZnO nanoparticles via Moringa oleifera green synthesis: physical properties \& mechanism of formation. Appl Surf Sci. 2017;406:339-47.

4. Baskoutas S, Giabouranis P, Yannopoulos SN, Dracopoulos V, Toth L, Chrissanthopoulous A, et al. Preparation of $\mathrm{ZnO}$ nanoparticles by thermal decomposition of zinc alginate. Thin Solid Films. 2007;515:8461-64. 
5. Chang PC, Fan Z, Wang D, Tseng WY, Chiou WA, Hong J, et al. $\mathrm{ZnO}$ nanowires synthesized by vapor trapping CVD method. Chem Mater. 2004;16:5133-37.

6. Meng Y, Lin Y, Lin Y. Electrodeposition for the synthesis of $\mathrm{ZnO}$ nanorods modified by surface attachment with $\mathrm{ZnO}$ nanoparticles and their dye-sensitized solar cell applications. Ceram Int. 2014;40:1693-98.

7. Lommens P, Van Thourhout D, Smet PF, Poelman D, Hens Z. Electrophoretic deposition of $\mathrm{ZnO}$ nanoparticles, from micropatterns to substrate coverage. Nanotechnology. 2008;19:245-301.

8. Siva Kumar S, Venkateswarlu P, Ranga Rao V, Nageswara Rao G. Synthesis, characterization and optical properties of zinc oxide nanoparticles. Int Nano Lett. 2013;3:30.

9. Pinjari DV, Pandit AB, Mhaske ST. Ultrasound assisted green synthesis of zinc oxide nanorods at room temperature. Indian J Chem. 2016;23:221-26.

10. Ismail RA, Ali AK, Ismail MM, Hassoon KI. Preparation and characterization of colloidal $\mathrm{ZnO}$ nanoparticles using nanosecond laser ablation in water. Appl Nanosci. 2011;1:45-9.

11. Gilani S, Ghorbanpour M, Jadid AP. Antibacterial activity of ZnO films by anodizing. J Nanostruct Chem. 2016;6:183-9.

12. Santhoshkumar J, Venkat Kumar S, Rajeshkumar S. Synthesis of zinc oxide nanoparticles using plant leaf extract against urinary tract infection pathogens. Resour Effic Technol. 2017;3:459-65.

13. Chaudhuri SK, Malodia L. Biosynthesis of zinc oxide nanoparticles using leaf extract of Calotropis gigantea: characterization and evaluation on tree seedling growth in nursery stage. Appl Nanosci. 2017;7:501-12.

14. Senthilkumar N, Nandhakumar E, Priya P, Soni D, Vimalan M, Vetha Potheher I. Synthesis of zinc oxide nanoparticles using leaf extract of Tectona grandis (L.) and their anti-bacterial, anti-arthritic, anti-oxidant and in vitro cytotoxicity activities. New J Chem. 2017;41:10347-56.

15. Jamdagni P, Khatri P, Rana JS. Green synthesis of zinc oxide nanoparticles using flower extract of Nyctanthes arbortristis and their antifungal activity. J King Saud Univ Sci. 2018;30:168-75.

16. Dobrucka R, Dlugaszewska J. Biosynthesis and antibacterial activity of $\mathrm{ZnO}$ nanoparticles using Trifolium pretense flower extract. Saudi J Biol Sci. 2016;23:517-23.

17. Nava OJ, Soto-Robles CA, Gomez-Gutierrez CM, VilchisNestor AR, Castro-Beltran A, Olivas A, et al. Fruit Peel extract mediated green synthesis of zinc oxide nanoparticles. J Mol Struct. 2017;1147:1-6.

18. Aminuzzaman M, Ying LP, Goh WS, Watanabe A. Green synthesis of zinc oxide nanoparticles using aqueous extract of Garcinia mangostana fruit pericarp and their photocatalytic activity. Bull Mater Sci. 2018;41:1-10.
19. Fazizadeh M, Khosravi R, Zarei A. Green synthesis of zinc oxide nanoparticles using Peganum harmala seed extract, and loaded on Peganum harmala seed powdered activated carbon as new adsorbent for removal of Cr (VI) from aqueous solution. Ecol Eng. 2017;103:180-90.

20. Raghavendra M, Yatish KV, Lalthamba HS. Plant-mediated green synthesis of $\mathrm{ZnO}$ nanoparticles using Garcinia gummi-gutta seed extract: photoluminescence, screening of their catalytic activity in antioxidant, formylation and biodiesel production. Eur Phys J Plus. 2017;132:1-12.

21. Kavitha S, Dhamodaran M, Prasad R, Ganesan M. Synthesis and characterization of zinc oxide nanoparticles using terpenoid fractions of Andrographis paniculata leaves. Int Nano Lett. 2017;7:141-47.

22. Yan JK, Wang YY, Zhu LL, Wu JY. Green synthesis and characterization of zinc oxide nanoparticles using carboxylic curdlan and their interaction with bovine serum albumin. RSC Adv. 2016;6:77752-59.

23. Yuvakumar R, Suresh J, Hong SI. Green synthesis of zinc oxide nanoparticles. Adv Mater Res. 2014;952:137-40.

24. Saravanakumar K, Muthuraj V, Vadivel S. Constructing novel Ag nanoparticles anchored on $\mathrm{MnO}_{2}$ nanowires as an efficient visible light driven photocatalyst. RSC Adv. 2016;6:61357-66.

25. Saravanakumar K, Muthuraj V, Jeyaraj M. The design of novel visible light driven $\mathrm{Ag} / \mathrm{CdO}$ as smart nanocomposite for photodegradation of different dye contaminants. Spectrochim Acta Part A. 2018;188:291-300.

26. Saravanakumar K, Mymoon Ramjan M, Suresh P, Muthuraj V. Fabrication of highly efficient visible light driven Ag/ $\mathrm{CeO}_{2}$ photocatalyst for degradation of organic pollutants. J Alloys Comps. 2016;664:149-60.

27. Montazer M, Amiri MM. Reactor on textiles and polymers: ex situ and in situ synthesis, application and characterization. J Phys Chem. 2014;118:1453-70.

28. Khaleel Basha S, Vijaya Lakshmi K, Sugantha Kumari V. Ammonia sensor and antibacterial activities of green zinc oxide nanoparticles. Sens Bio Sens Res. 2016;10:34-40.

29. Yin X, Wang B, He M, He T. Facile synthesis of $\mathrm{ZnO}$ nanocrystals via a solid state reaction for high performance plastic dye-sensitized solar cells. Nano Res. 2012;5:1-10.

30. Lu PJ, Huang SC, Chen YP, Chiueh LC, Chih Shih DY. Analysis of titanium dioxide and zinc oxide nanoparticles in cosmetics. J Food Drug Anal. 2015;23:587-94.

31. Osmond MJ, Mccall MJ. Zinc oxide nanoparticles in modern sunscreens: an analysis of potential exposure and hazard. J Nanotechnol. 2010;4:15-41.

32. Rasmussen JW, Martinez E, Louka P, Wingett DG. Zinc oxide nanoparticles for selective destruction of tumor cells and potential for drug delivery applications. Expert Opin Drug Deliv. 2010;7:1063-77. 
33. Premanathan M, Karthikeyan K, Jeyasubramanian K, Manivannan G. Selective toxicity of $\mathrm{ZnO}$ nanoparticles toward Gram-positive bacteria and cancer cells by apoptosis through lipid peroxidation. Nanomed Nanotechnol Biol Med. 2011;7:184-192.

34. Sharma Prince P, Roy Ram K, Anurag GD, Sharma VK. Hyptis suaveolens (L.) Poit: a phyto-pharmacological review. Int J Chem Pharm Sci. 2013;4:1-11.

35. Sangeetha G, Rajeshwari S, Venckatesh R. Green synthesis of zinc oxide nanoparticles by Aloe barbadensis miller leaf extract: structure and optical properties. Mater Res Bull. 2011;46:2560-66.
36. Abdul Salam H, Sivaraj R, Venckatesh R. Green synthesis and characterization of zinc oxide nanoparticles from Ocimum basilicum L.var. purpurascens Benth-Lamiaceae leaf extract. Mater Lett. 2014;131:16-18.

37. Azizia S, Ahmada MB, Namvar F, Mohamad R. Green biosynthesis and characterization of zinc oxide nanoparticles using brown marine macroalga Sargassum muticum aqueous extract. Mater Lett. 2014;116: 275-77.

38. Alessio B, Maximilian D, Pierandrea LN, Piero B. Synthesis and characterization of zinc oxide nanoparticles: application to textiles as UV-absorbers. J Nanopart Res. 2008;10:679-89. 